\title{
EFFECT OF NOISE GENERATED BY THE WIND TURBINE ON THE QUALITY OF GOOSE MUSCLES AND ABDOMINAL FAT*
}

\author{
Małgorzata Karwowska ${ }^{1 \bullet}$, Jan Mikołajczak², Sylwester Borowski³, Zbigniew Józef Dolatowski ${ }^{1}$, \\ Joanna Marć-Pieńkowska², Waldemar Budziński ${ }^{2}$ \\ 'Department of Meat Technology and Food Quality, University of Life Sciences in Lublin, \\ Skromna 8, 20-704 Lublin, Poland \\ ${ }^{2}$ Faculty of Animal Breeding and Biology, University of Technology and Life Sciences in Bydgoszcz, \\ Kordeckiego 20, 85-225 Bydgoszcz, Poland \\ ${ }^{3}$ Faculty of Mechanical Engineering, University of Technology and Life Sciences in Bydgoszcz, \\ Kordeckiego 20, 85-225 Bydgoszcz, Poland \\ •Corresponding author: malgorzata.karwowska@up.lublin.pl
}

\begin{abstract}
The objective of this study was to assess the physicochemical properties of breast and thigh muscles and fatty acid composition of abdominal fat of geese reared at a distance of 50 metres from the wind turbine compared to those reared $\mathbf{4 6 0}$ metres from the wind turbine. The study was carried out on 40 Koluda White ${ }^{\circledast}$ geese (Anser anser $f$. domestica) divided into two groups: Treatment 1 reared at a distance of 50 metres and Treatment 2 - reared at a distance of 460 metres from the wind turbine (Vestas V90 wind turbine). The muscles were analysed for $\mathrm{pH}$, thermal loss, shear force, TBARS values and colour parameters $\left(L^{*} a^{*} b^{*}\right)$. The fatty acids composition of abdominal fat was also analysed. The results of the present study suggest that noise generated by the wind turbine affected the quality of muscles and the fatty acid profile of abdominal fat of geese. The results showed that the muscles of geese reared at a distance of $\mathbf{5 0}$ metres from the wind turbine were characterized by higher $\mathrm{pH}$ and TBARS values compared to those reared at a longer distance from the wind turbine. The significantly lower content of $\mathrm{C} 18: 3 n-3$ fatty acid in abdominal fat was observed for geese reared $\mathbf{5 0}$ metres from the wind turbine. Further studies should be undertaken to establish the safe distance of a wind turbine from livestock buildings.
\end{abstract}

Key words: goose, stress, breast and leg muscles quality, abdominal fat

Consumers have recently shown an increasing interest in safer and more nutritious food products which improve health. Products with a higher ratio of unsaturated fatty acids, especially $n-3$ fatty acids are desired because these lipids can help prevent the development of cardiovascular and inflammatory pathologies (Bou et al.,

\footnotetext{
*This work was financed from DS VKM-DS-1 University of Life Sciences in Lublin.
} 
2009). In this regard, goose meat and fat are very valuable food due to the fact that it is rich in unsaturated fatty acids and low in cholesterol (Schmid, 2011; Yanovych et al., 2013).

Goose fat is rich in oleic acid which can lower blood cholesterol levels (Wood et al., 2003) as well as vitamins and minerals. Due to the considerable content of oleic, linoleic, linolenic and arachidonic acids goose fat is considered the safest animal fat (Wężyk et al., 2003). The results of many studies have proved that polyenic fatty acids stimulate the cardiovascular system, as well as playing a key role in the development of nervous system during intrauterine life and in early childhood (MarciniakŁukasiak, 2011).

The chemical composition of goose muscles depends on many factors, including, among others, rearing conditions, nutrition, handling and slaughter related processes. It is well documented that stress caused by feed and water deprivation or environmental conditions affect the quality of meat (Kowalska et al., 2011). The changes in meat caused by stress depend on both duration and intensity of the stress period (Okruszek et al., 2008). Based on the literature, intense and long-lasting stress induces disorders of the daily rhythm of hormones secretion, physiological and morphological changes resulting in changes of blood composition, muscle tissue and formation of meat defects (Ognik and Sembratowicz, 2012) affecting its usefulness for processing. The environmental stress, including heat stress, has been associated with increased lipid peroxidation in serum and the liver and decreased concentrations of antioxidant vitamins in poultry (Sahin et al., 2005). Stress leads to the generation of free radicals which can damage cell membranes by inducing lipid peroxidation of polyunsaturated fatty acids in the cell membrane, destroying membrane integrity (Ognik and Sembratowicz, 2012).

Wind turbines are among environmental factors that generate noise, infrasound or shadow flicker which could adversely affect animals living in their neighbourhood. There are many reports in the world literature providing the relationship between wind turbines and health effects (Knopper and Ollson, 2011; Leventhall et al., 2003; Saidur et al., 2011). The energy derived from wind has played a vital role in the history of mankind and is again receiving considerable attention. It has become the fastest growing energy source, because of its free and non-polluting character. Annual installations of wind power have increased steadily over the last 17 years from $814 \mathrm{MW}$ in 1995 to $9,616 \mathrm{MW}$ in 2011 , an average annual growth rate of $15.6 \%$. During 2011, 10,281 MW of wind power was installed across Europe, of which $436 \mathrm{MW}$ was in Poland (EWEA, 2011). As the number of wind turbines in Poland has been increasing, the problem of the impact of wind turbines on living organisms also increased.

As the importance of goose meat and fat increased, it is necessary to pay more attention to the conditions of goose meat and fat production. Based on the literature describing the impact of wind turbines on health we hypothesized that goose muscles and fat derived from birds reared near a wind turbine can be characterized by altered properties determining its suitability for processing and hence the quality of products. The objective of this study was to assess and compare selected quality parameters of breast and thigh muscles and fatty acid composition of abdominal fat 
of White Koluda ${ }^{\circledR}$ geese reared at a distance of 50 and 460 metres from the wind turbine. To our knowledge, the scientific literature does not contain information regarding the impact of wind turbines on farm animals in terms of the quality of meat for processing. The investigation is part of a study on the impact of wind turbines on the organisms living in their vicinity.

\section{Material and methods}

\section{Animals and breeding conditions}

The study was carried out on 40 White Kołuda geese (Anser anser $f$. domestica). The geese were purchased from the National Research Institute of Animal Production in Kołuda Wielka. The experiment lasted 17 weeks. During the test period geese were reared up to 5 weeks of age in a brooder house in controlled air temperature and in conditions free from the impact of noise from a wind turbine. Next, experimental geese were randomly divided into two groups of 20 birds (with sex ratio of 1:1) and were placed in two identical pens. Pen I (Treatment 1) was placed in the close distance $(50 \mathrm{~m})$ to the wind turbine to ensure the most adverse conditions for birds. Pen II (Treatment 2) was placed in the farm, $460 \mathrm{~m}$ from the wind turbine. This distance is generally accepted in the Kujawsko-Pomorskie province and considered to be safe. The birds were kept in roofed pens with access to free range. The geese from two treatments were fed on the same complete feeds. The commercial mixtures contained: $12 \mathrm{MJ}$ metabolizable energy (1-4 weeks of age), 11.5 MJ metabolizable energy (5-8 weeks of age), and 11.3 MJ metabolizable energy (9-14 weeks of age). In order to prepare the geese for oat fattening, daily rations were diminished at 14 weeks of age. At the end of rearing (15-17 weeks), geese were fed only with oat grains provided ad libitum. Water was provided ad libitum.

At 17 weeks of age, geese were weighed and slaughtered. Body weight of geese at 17 weeks of age is given in Table 1. Twelve hours before slaughter birds were only allowed access to water. Birds were slaughtered in a local slaughterhouse in Świniarzewo according to relevant regulations applied in the poultry industry. The Local Ethics Committee for Experiments with Animals approved all of the experimental procedures relating to the use of live animals.

Table 1. Pre-slaughter body weight of 17-week-old geese $(\mathrm{kg})$

\begin{tabular}{l|c}
\hline Treatment group & Body weight $(\mathrm{kg})$ \\
\hline Treatment 1 & $7.45 \pm 0.59$ \\
Treatment 2 & $8.31 \pm 0.84$ \\
\hline
\end{tabular}

\section{Measurements of noise generated by wind turbine}

For the purposes of the experiment, noise generated by the wind turbine was measured. Vestas V90 wind turbine with rated power of $2 \mathrm{MW}$ was the source of noise. Two different scales were used to weigh all frequencies that are emitted by the 
wind turbine. Most audible noises in the range of 200-20,000 $\mathrm{Hz}$ weighed with the A scale, $d B(A)$. Infrasound weighed with the $\mathrm{G}$ scale, $d B(G)$. The noise was measured in pens I and II in 5 replicates. The results are presented in Figure 1. The average noise values obtained near the wind turbine (pen I) were higher than those obtained at the distance of $460 \mathrm{~m}$ from the turbine (pen II).
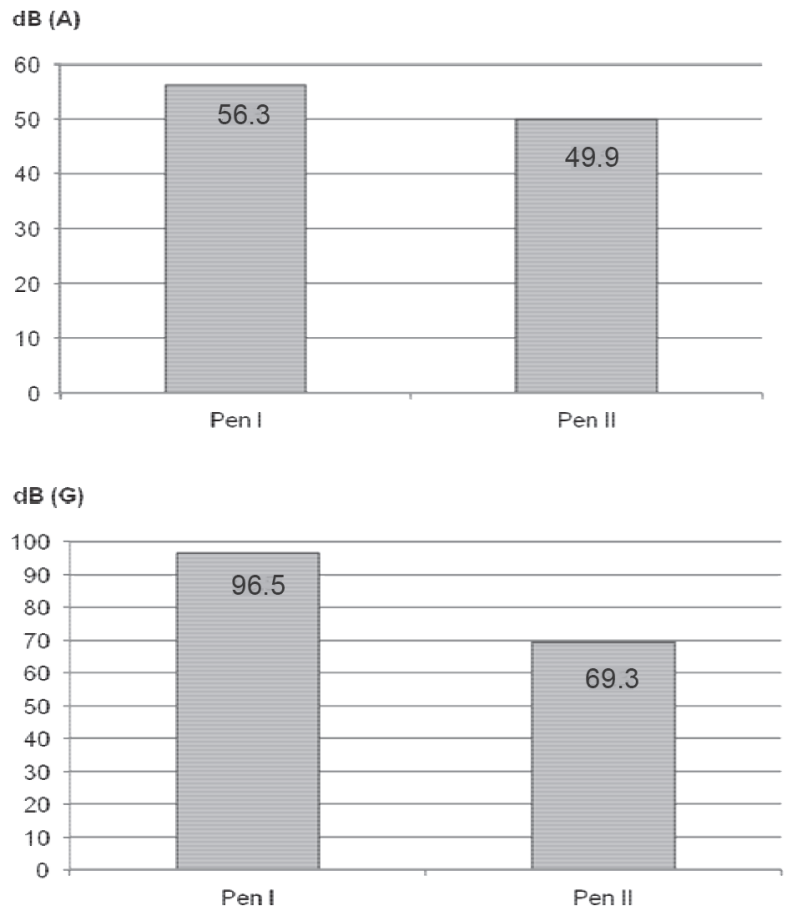

Figure 1. The mean values obtained during the noise measurement, $\mathrm{A}$ - in the A scale, $\mathrm{B}$ - in the $\mathrm{G}$ scale

\section{Muscles and abdominal fat preparation}

The carcasses were cooled and stored at a temperature of about $8-10^{\circ} \mathrm{C}$ for 48 hours until further analysis. The samples of breast, thigh muscles and abdominal fat were separated from carcasses. Breast and thigh muscles were analysed for $\mathrm{pH}$, TBARS values and colour parameters $\left(\mathrm{L}^{*} \mathrm{a}^{*} \mathrm{~b}^{*}\right)$. Abdominal fat was packed individually into HDPE bags and stored at $-24^{\circ} \mathrm{C}$ until analysis of fatty acids composition (7-8 days).

\section{Measurement of $\mathbf{p H}$}

The $\mathrm{pH}$ was measured in a water homogenate made by comminuted $10 \mathrm{~g}$ of minced sample with $100 \mathrm{ml}$ of distilled water for $1 \mathrm{~min}$, using a homogenizer (IKA ULTRA-TURRAX T25 Basic, Germany). The resulting suspension was allowed to stand for $5 \mathrm{~min}$ before the $\mathrm{pH}$ was measured with a digital pH-meter CPC-501 (Elmetron, Poland) equipped with a $\mathrm{pH}$ electrode (ERH-111, Hydromet, Poland). The 
$\mathrm{pH}$-meter was standardized with buffer solutions at $\mathrm{pH} 4.0,7.0$ and 9.0, before $\mathrm{pH}$ measurements.

\section{Thermal loss determination}

The breast and thigh muscle samples (about $80 \pm 2 \mathrm{~g}$ ) were cured using $2.0 \%$ curing mixture $\left(99.5 \% \mathrm{NaCl}, 0.05 \%\right.$ sodium nitrite) at $4{ }^{\circ} \mathrm{C}$ for 24 hours. The samples were individually wrapped in the aluminium sheet and placed in the oven for roasting at $180^{\circ} \mathrm{C}$ to an internal temperature of $72^{\circ} \mathrm{C}$. The temperature was monitored by the chromium-aluminium thermocouples. The muscle samples were cooled and blotted dry. Total thermal loss was estimated by weighing samples before and after thermal treatment. Total thermal loss was expressed as a percentage of the initial raw mass. The weight of each sample was recorded before and after thermal treatment. Thermal loss was expressed as the percentage of the weight difference after thermal treatment.

\section{Shear force measurements}

Heat-treated muscle samples were used for shear force measurements. Preparation of heat-treated muscle samples for Warner-Bratzler shear force was similar to the procedure for thermal loss. Four cylindrical cores $(1.25 \mathrm{~cm}$ diameter $)$ were cut from the muscle, parallel to the longitudinal orientation of the muscle fibres. WarnerBratzler shear force was determined using a texture analyser TA-XT plus (Stable Micro Systems Ltd. Surrey, UK) equipped with a V-shaped Warner-Bratzler device

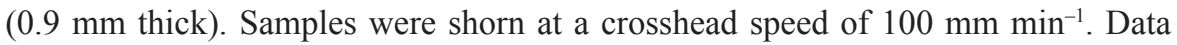
were collected with Texture Expert Exceed Software (Stable Micro Systems).

\section{Measurements of thiobarbituric acid reactive substances (TBARS)}

The extent of lipid oxidation was determined in muscles by measuring the TBAreactive substances according to the procedure proposed by Pikul et al. (1989). Values were expressed as mg of malondialdehyde per kilogram of sample.

\section{Colour measurements}

Colour $\left(\mathrm{L}^{*} \mathrm{a}^{*} \mathrm{~b}^{*}\right)$ was assessed on the freshly cut surface of muscles using an XRite Color ${ }^{\circledR}$ Premiere 8200 colorimeter (X-Rite Incorporated, Michigan, USA) with a D65 illuminant and a $10^{\circ}$ standard observer (AMSA, 1991). Samples for colour measurements were $5 \mathrm{~cm}$ thick and excited at the depth of $20 \mathrm{~mm}$. Before colour determination, muscle samples were wrapped in an oxygen permeable polyethylene film. Every time before use, the instrument was standardized against a white ceramic calibration tile with the specification of $\mathrm{L}^{*}=95.87, \mathrm{a}^{*}=-0.49, \mathrm{~b}^{*}=2.39$ that was wrapped in the same polyethylene film used for the muscle samples, and a light trap.

\section{Fatty acid analysis}

The Folch method (Folch et al., 1956) was used for the extraction of lipids from abdominal fat. The fatty acid composition was determined by capillary gas chromatography. For the determination of FA profile the lipid samples were converted to 
their corresponding methyl esters by the AOAC official method Ce 2-66 (AOCS, 1997). The FA methyl esters (FAME) were quantified by gas chromatography using a fused silica capillary column (Select ${ }^{\mathrm{TM}}$ Biodiesel for FAME, Varian, USA) $(30 \mathrm{~m} \times 0.32 \mathrm{~mm} \times 0.25 \mu \mathrm{m}$ film thickness) and flame-ionization detector in Varian 450-GC (Varian, USA) at injection volume of $1 \mathrm{~mL} / \mathrm{min}$ and split ratio of 1/50, respectively. Helium was used as the carrier gas at a head pressure of $2.5 \mathrm{~mL} / \mathrm{min}$ constant flow. Air, hydrogen and helium make-up gas flow rates by flame-ionization detector were: 300,30 and $28 \mathrm{~mL} / \mathrm{min}$, respectively. The detector and injector temperatures were chosen as $300^{\circ} \mathrm{C}$ and $250^{\circ} \mathrm{C}$, respectively. The initial column temperature of $150^{\circ} \mathrm{C}$ was held for $1 \mathrm{~min}$, increased to $200^{\circ} \mathrm{C}$ at $3^{\circ} \mathrm{C} / \mathrm{min}$ and held for $10 \mathrm{~min}$. Then, it was increased to $240^{\circ} \mathrm{C}$ at the rate of $3^{\circ} \mathrm{C} / \mathrm{min}$ and maintained for 4 min. Quantification of adipose lipid FAMEs was carried out using nonadecanoic acid (C 19:0) as an internal standard. Fatty acid identification was done by comparing retention time of the peaks with those known for the standard (Supelco 37 FAME Mix C 4-C 24 Component, Sigma-Aldrich, St. Luis, USA). Peak identification was performed using the Galaxie Chromatography Data System (Varian, Palo Alto, Calif., USA).

\section{Statistical analysis}

The data were analysed by one-way ANOVA with two levels of experimental factor (Treatment I and Treatment II, respectively) according to the linear model:

$$
Y_{i j}=\mu+A_{j}+e_{i j}
$$

where:

$Y_{i j}-$ is the value of trait,

$\mu-$ is the overall mean,

$A_{j}-$ is the effect of treatments (Treatment I and Treatment II),

$e_{i j}-$ is the random observation error.

The results were presented in tables as mean values (x) and standard deviations (SD) of the means. The significance of differences between means for the investigated parameter were determined (at the significance level $\mathrm{P}<0.05$ ) by T-Tukey's multiple range test. Measurements were carried out in three replications for each sample.

\section{Results}

The examination of the $\mathrm{pH}$ values of breast muscles indicated statistically significant differences between treatments (Table 2). Breast muscles of geese reared at the distance of 50 metres from the wind turbine were characterized by higher $\mathrm{pH}$ values compared to those reared 460 metres from the wind turbine. As far as results of measurements of thigh muscles are concerned, no statistical differences were observed in $\mathrm{pH}$ values across treatments. 
Table 2. $\mathrm{pH}$ values of breast and thigh muscles of geese

\begin{tabular}{lc|c}
\hline \multicolumn{1}{c|}{ Treatment group } & Breast muscles & Thigh muscles \\
\hline Treatment 1 & $6.14 * \pm 0.10$ & $6.60 \pm 0.05$ \\
Treatment 2 & $5.78 * \pm 0.12$ & $6.50 \pm 0.10$ \\
\hline
\end{tabular}

*statistically significant differences in columns between treatment groups $(\mathrm{P}<0.05)$.

Table 3. Thermal loss (\%) of breast and thigh muscles of geese

\begin{tabular}{l|c|c}
\hline \multirow{2}{*}{ Treatment group } & \multicolumn{2}{c}{ Thermal loss $(\%)$} \\
\cline { 2 - 3 } & breast muscles & thigh muscles \\
\hline Treatment 1 & $27.48 \pm 1.72$ & $25.59 \pm 3.91$ \\
Treatment 2 & $26.87 \pm 3.34$ & $23.83 \pm 2.61$ \\
\hline
\end{tabular}

A statistically significant difference between treatment groups was not detected $(\mathrm{P}<0.05)$.

Table 3 gives results for the thermal loss of thigh and breast muscles. Statistical analysis showed no significant differences $(\mathrm{P}<0.05)$ in thermal loss in the meat of geese from different treatments. Results of shear force measurements revealed that breast muscle of geese reared 50 metres from the wind turbine was characterized by higher shear force compared to those reared at a longer distance from the wind turbine (Table 4). For the thigh muscles, no statistical differences were observed in shear force values across treatments.

Table 4. Shear force (N) of breast and thigh muscles of geese

\begin{tabular}{l|c|c}
\hline \multirow{2}{*}{ Treatment group } & \multicolumn{2}{|c}{ Shear force $(\mathrm{N})$} \\
\cline { 2 - 3 } & breast muscles & thigh muscles \\
\hline Treatment 1 & $57.6^{*} \pm 3.7$ & $64.8 \pm 3.1$ \\
Treatment 2 & $49.8^{*} \pm 3.3$ & $62.2 \pm 4.1$ \\
\hline
\end{tabular}

*statistically significant differences in columns between treatment groups $(\mathrm{P}<0.05)$.

The extent of lipid oxidation in breast muscles varied depending on rearing conditions (Table 5). The results showed that the breast muscles of geese reared 50 metres from the wind turbine were characterized by higher TBARS values compared to those reared at a longer distance from the wind turbine. As far as measurements of thigh muscles are concerned, similar results were obtained for Treatment 1 and Treatment 2.

Table 5. TBARS values of breast and thigh muscles of geese

\begin{tabular}{l|c|c}
\hline \multirow{2}{*}{ Treatment group } & \multicolumn{2}{|c}{ TBARS $(\mathrm{mg} / \mathrm{kg})$} \\
\cline { 2 - 3 } & breast muscles & thigh muscles \\
\hline Treatment 1 & $1.96^{*} \pm 0.09$ & $1.35 \pm 0.13$ \\
Treatment 2 & $1.65^{*} \pm 0.16$ & $1.17 \pm 0.11$ \\
\hline
\end{tabular}

*statistically significant differences in columns between treatment groups $(\mathrm{P}<0.05)$. 
Table 6. Colour parameters of breast and thigh muscles of geese

\begin{tabular}{l|c|c|c}
\hline & Treatment group & Breast muscles & Thigh muscles \\
\hline L* colour parameter & Treatment 1 & $37.44 \pm 2.88$ & $39.98 \pm 2.48$ \\
& Treatment 2 & $37.95 \pm 2.38$ & $38.55 \pm 2.66$ \\
a* colour parameter & Treatment 1 & $12.46 \pm 1.68$ & $8.78 \pm 1.98$ \\
& Treatment 2 & $11.94 \pm 1.14$ & $9.11 \pm 1.46$ \\
b* colour parameter & Treatment 1 & $7.96 \pm 2.02$ & $7.42 \pm 1.23$ \\
& Treatment 2 & $7.36 \pm 1.18$ & $7.45 \pm 1.26$ \\
\hline
\end{tabular}

A statistically significant difference between treatment groups was not detected $(\mathrm{P}<0.05)$.

The meat colour parameters $\mathrm{L}^{*} \mathrm{a}^{*} \mathrm{~b}^{*}$ are presented in Table 6 . Rearing geese near the wind turbine did not cause significant changes in lightness $\left(\mathrm{L}^{*}\right)$, redness $\left(\mathrm{a}^{*}\right)$ and yellowness $\left(b^{*}\right)$ of meat. Both breast and thigh muscles were characterized by similar results of colour parameters between treatments.

Table 7. Fatty acid composition of abdominal fat of geese (\%)

\begin{tabular}{c|r|r}
\hline & Treatment I & Treatment II \\
\hline$\Sigma$ SFA & & \\
$14: 0$ & $0.27 \pm 0.07$ & $0.37 \pm 0.04$ \\
$16: 0$ & $20.86 \pm 3.10$ & $22.89 \pm 0.93$ \\
$17: 0$ & $0.08 \pm 0.01$ & $0.09 \pm 0.01$ \\
total & $21.24 \pm 3.23$ & $23.42 \pm 0.98$ \\
$\Sigma$ MUFA & & \\
$16: 1$ & $2.46 \pm 0.57$ & $2.48 \pm 0.27$ \\
$18: 1$ & $64.53 \pm 3.88$ & $62.33 \pm 2.23$ \\
$20: 1$ & $0.33 \pm 0.03$ & $0.38 \pm 0.04$ \\
total & $67.32 \pm 3.78$ & $65.17 \pm 1.99$ \\
$\Sigma$ PUFA & & \\
$18: 2$ & $10.74 \pm 0.52$ & $9.62 \pm 1.03$ \\
$18: 3$ & $0.52 * \pm 0.04$ & $1.59 * \pm 0.02$ \\
total & $11.32 \pm 0.56$ & $11.27 \pm 1.00$ \\
\hline
\end{tabular}

*statistically significant differences in rows between treatment groups $(\mathrm{P}<0.05)$.

The fatty acids composition of abdominal fat of geese is summarized in Table 7. In both treatment groups of geese, SFA and MUFA were the predominant components in lipids of abdominal fat, whereas the concentration of PUFA was relatively lower. No significant differences were noted in SFA, MUFA as well as total PUFA values between abdominal fat from Treatment 1 and 2 . The significantly lower content of C 18:3 fatty acid in abdominal fat was observed in the case of geese reared 50 metres from the wind turbine. In abdominal fat of experimental geese, long-chain polyunsaturated fatty acids (PUFAs), including C 20:3 n-3 - EPA and C 22:6n-3DHA were not observed. 


\section{Discussion}

The wind turbines undoubtedly provide many benefits to man but they are not free from negative effects (Saidur et al., 2011). There is a close relationship between the impact of wind farms and health, because wind turbines can generate stressors. According to Leventhall (2009), any persistent and unwanted sound (both low frequency and high frequency) is a stressor. The low-frequency noise generated by public infrastructure including wind turbines may have serious health effects like vertigo, disturbed sleep, stress, hypertension, and heart rhythm disorders (Leventhall et al., 2003). The measurements of wind turbine noise in the current research revealed that level of audible noise as well as infrasound is higher in pen I situated $50 \mathrm{~m}$ away from the wind turbine compared to pen II located $460 \mathrm{~m}$ from wind turbine.

Due to the lack of regulations in Poland, wind turbines are often built in close proximity to residential areas and livestock buildings. The distance of $500 \mathrm{~m}$ is generally accepted in the Kujawsko-Pomorskie province and considered to be safe. Thus, animals are exposed to long-lasting stressors generated by wind turbines. In consequence, various questions arise related to animal metabolism that affect the quality of meat. To our knowledge, the scientific literature does not contain information regarding the impact of noise generated by wind turbines on the quality of meat from animals that are exposed to noise. A few studies have discussed the effect of other stressors on poultry meat quality (Dadgar et al., 2011, 2012).

On the basis of the results obtained, it can be concluded that raising geese in close proximity to a wind turbine impacts on $\mathrm{pH}$, shear force and TBARS values of breast muscle. In the case of thigh muscles no statistical differences were observed in these properties across treatments. In poultry, meat is classified as either white or dark, based on the overall colour of the muscle. Dark muscle has a high proportion of red fibres, compared with white muscle that is almost entirely composed of white fibres (Barbut, 2002). Red fibres have more and larger mitochondria, have more myoglobin, but are low in glycogen content in comparison to white fibres. The differences in muscle fibre type between the breast and thigh muscles of geese could result in differences in combating stress and result in alterations in postmortem metabolism between two fibre types and affect the muscles quality. In geese, breast muscles are darker and more red than thigh muscles as is evident from the results obtained from the measurements of colour parameters. The more pronounced effect of noise exposure on quality attributes of breast muscles in comparison to thigh muscles was speculated to be the result of differences in muscle fibre type.

The results of the present study indicated that breast muscle of geese exposed to higher levels of noise was characterized by significantly higher $\mathrm{pH}$ value. In the case of thigh muscles the effect of noise was not observed. The results obtained are in agreement with the findings of Dadgar et al. (2011), who indicated that extreme cold temperature before slaughter resulted in higher $\mathrm{pH}$ value of breast muscles.

Lipid oxidation is one of the major deteriorative processes which occur in meat during storage. Lipid oxidation products are known to interact in complex food systems and share a wide variety of undesirable reactions responsible for nutritional and sensory value changes as well as the formation of potentially toxic compounds 
(Morisey et al., 1998). It is believed that oxidative reactions affect the digestibility and water holding capacity of muscle proteins as well as the post-mortem tenderization (Bertram et al., 2007; Estévez, 2011). The present study showed that the muscles of geese reared at the distance of 50 metres from the wind turbine were characterized by significantly higher lipid oxidation as reflected by TBARS value and higher shear force compared to those reared further away from the wind turbine. The results reported by Sahin et al. (2005) also indicated that environmental stress including heat stress has been associated with increased lipid peroxidation in serum and liver and decreased concentrations of antioxidant vitamins in poultry.

The fatty acid composition of abdominal fat is important for two main reasons: it determines nutritional value and it affects many aspects of meat quality, including shelf life and oxidative stability (Wood et al., 2003). Generally, rearing geese in close proximity to a wind turbine impacts $\mathrm{C} 18: 3 n-3$ fatty acid content of abdominal fat. In the present study, birds reared at the distance of 50 metres from the wind turbine were characterized by a lower content of $n-3$ fatty acids in abdominal fat. The concentration of C 18:3n-3 fatty acid in abdominal fat of geese from Treatment II was higher than that reported by Okruszek (2011) for Rypińska and swan geese.

From the nutritional and physiological points of view it is very important to keep the high level of $n-3$ polyunsaturated fatty acids. $n-3$ PUFAs have been reported to have positive effects on human health including the potential to reduce the risk of cardiovascular disease, Alzheimer disease, atherosclerosis, obesity, type II diabetes, osteoporosis, dry eye syndrome (McAfee et al., 2010), and depression in adolescents with eating disorders (Swenne et al., 2011).

The increasing number of wind farms in Poland seems to be inevitable given the international legal responsibility to reduce $\mathrm{CO}_{2}$ emissions. However, this gives rise to many concerns over the impacts on the health of livestock and thus the quality of meat. It is crucial for wind turbines to be designed and planned carefully. The results of the present study suggest that noise generated by wind turbine affects the quality of muscles and fat of geese. It can generally be stated that raising geese in close proximity to the wind turbine resulted in higher $\mathrm{pH}$, shear force and TBARS values of breast muscle as well as lower content of C 18:3n-3 fatty acid of abdominal fat. In this sense, it is crucial to reduce the impact of noise generated by wind turbines on the quality of meat from animals that are exposed to noise. Therefore, further studies should be undertaken to establish the safe distance of a wind turbine from livestock buildings.

\section{References}

AMSA (1991). Guidelines for meat color evaluation. Proc. 44th Annual Reciprocal Meat Conference, National Livestock and Meat Board, and American Meat Science Association, pp. 232-249.

AOCS (1997). Official Methods and Recommended Practices of the American Oil Chemists' Society. AOCS Press, Champaign, USA, pp. 1-2.

B a r b u t S. (2002). Poultry Products Processing (An Industry Guide). CRC Press LLC, Boca Raton, FL.

B ertram H.C., Kristensen M., Østdal H., Baron C.P., Young J.F., Andersen H.J. (2007). Does oxidation affect the water functionality of myofibrillar proteins? J. Agric. Food Chem., 55: $2342-2348$. 
B ou R., Codony R., Tres A., D e cker E.A., Guardiola F. (2009). Dietary strategies to improve nutritional value, oxidative stability, and sensory properties of poultry products. Crit. Rev. Food Sci. Nutr., 49: 800-822.

D a d g a r S., L e e E.S., L e e r T.L.V., C l a s s e n H.L., C r ow e T.G., S h and P.J. (2011). Effect of acute cold exposure, age, sex, and lairage on broiler breast meat quality. Poultry Sci., 90: 444-457.

D a d g a r S., C row e T.G., C l a s s e n H.L., Watt s J.M., S h a n d P.J. (2012). Broiler chicken thigh and breast muscle responses to cold stress during simulated transport before slaughter. Poultry Sci., 91: 1454-1464.

Es tév e z M. (2011). Protein carbonyls in meat systems: A review. Meat Sci., 89: 259-279.

Folch J., L e es M., Stan ley G.H. (1956). A simple method for the isolation and purification of total lipids from animal tissues. J. Biol. Chem., 226: 497-509.

Kn op per L.D., O11 s o n C.A. (2011). Health effects and wind turbines: a review of the literature. Environm. Health, 10: 2-10.

Kow a ls ka D., Gu g ołe k A., B i e lańs ki P. (2011). Effect of stress on rabbit meat quality. Ann. Anim. Sci., 11: 465-475.

Leventhall G. (2009). Low frequency noise. What we know, what we do not know, and what we would like to know. J. Low Freq. Noise, Vibr. Active Contr., 28: 79-104.

Leventhall G., P e $1 \mathrm{~m}$ e ar P., B e n t on S. (2003). A review of published research on low frequency noise and its effects. Report for Department for Environment, Food and Rural Affairs, London.

Mar c in iak- Ł uka siak K. (2011). Role and importance of omega-3 fatty acids (in Polish). Food. Science. Technology. Quality, 6: 24-35.

McAfee A.J., McSorley E.M., Cuskelly G.J., Moss B.W., Wallace J.M.W., Bonh a m M.P., F e a r o n A.M. (2010). Red meat consumption: An overview of the risks and benefits. Meat Sci., 84: 1-13.

Mor i s e y P.A., S h e eh y P.J.A., Ga lvin K., Ke r ry J.P., B u c k l e y D.J. (1998). Lipid stability in meat and meat products. Meat Sci., 49: S57-S86.

O g n i k K., S e m br a t o w i c z I. (2012). Stress as a factor modifying the metabolism in poultry. Ann. UMCS Zoot., 30: 34-43.

O k r u s z e k A. (2011). Comparison of fatty acids content in muscles and abdominal fat lipids of geese from different flocks. Arch. Geflügelk., 75: 61-66.

Okruszek A., Ks iążkiewicz J., Wołoszyn J., Harf G., Orkusz A., Szukalski G. (2008). Changes in selected physicochemical parameters of breast muscles of geese from Polish conservation flocks depending on duration of the post slaughter period. Archiv. Tierzucht. Dummersdorf, 51: 255-265.

Pikul J., Leszczyński D.E., Kummerow F.A. (1989). Evaluation of three modified TBA methods for measuring lipid oxidation in chicken meat. J. Agric. Food Chem., 37: 1309-1315.

S ah in K., S m ith M.O., Onderci M., S a h in N., Gursu M.F., Kucuk D.O. (2005). Supplementation of zinc from organic or inorganic source improves performance and antioxidant status of heat-distressed quail. Poultry Sci., 84: 882-887.

S a id ur R., R a h im N.A., I s l a m M.R., S o l a ng i K.H. (2011). Environmental impact of wind energy. Renew. Sust. Ener. Rev., 15: 2423-2430.

S c h m id A. (2011). The role of meat in the human diet. Crit. Rev. Food Sci. Nutr., 51: 50-66.

Swe nne I., Ros ling A., Teng bla d S., Ves s by B. (2011). Omega-3 polyunsaturated essential fatty acids are associated with depression in adolescents with eating disorders and weight loss. Acta Pediatr. Int. J. Pediatr., 100: 1610-1615.

W ęży k S., R o s ińs ki A., B i e lińs k a H., B a c o w s k i J., C y w a - B e n k o K. (2003). A note on the meat quality of W11 and W33 White Kołuda geese strains. Anim. Sci. Pap. Rep., 3: 192-199.

Wood J.D., Richards on R.I., Nute G.R.A., F is her V., Campo M.M., K a s a pidou E. (2003). Effects of fatty acids on meat quality: A review. Meat Sci., 66: 21-32.

Yanovy ch D., C z e c h A., Z a s a d n a Z. (2013). The effect of dietary fish oil on the lipid and fatty acid composition and oxidative stability of goose leg muscles. Ann. Anim. Sci., 13: 155-165.

Received: 19 VII 2013

Accepted: 7 X 2013 